\title{
Phenolic acid content, antioxidant properties, and antibacterial potential of flowers and fruits from selected Pakistani indigenous medicinal plants
}

\author{
Syed Ali Raza Naqvia ${ }^{a, *}$, Rifaqat Waseem ${ }^{\mathrm{a}}$, Nasir Mahmood ${ }^{\mathrm{b}}$, Zaib Hussain ${ }^{\mathrm{c}}$, Zulfiqar Ali Khan ${ }^{\mathrm{a}}$, \\ Sohail Anjum Shahzad ${ }^{\mathrm{d}}$, Muhammad Yar ${ }^{\mathrm{e}}$, Rashid Amin ${ }^{\mathrm{e}}$, Shazia Anwer Bukhari ${ }^{\mathrm{a}}$, \\ Ameer Fawad Zahoor ${ }^{\mathrm{a}}$, Sadia Javed ${ }^{\mathrm{a}}$, Abdullah Ijaz Hussain ${ }^{\mathrm{f}}$ \\ ${ }^{a}$ Department of Chemistry, Government College University, Faisalabad-38000, Pakistan \\ b Department of Allied Health Sciences and Chemical Pathology, University of Health Sciences, \\ Lahore-54000, Pakistan \\ ${ }^{c}$ Institute of Chemistry, University of the Punjab, Lahore-5400, Pakistan \\ ${ }^{d}$ Department of Chemistry, COMSATS Institute of Information Technology, Abbottabad-22060, Pakistan \\ e Interdisciplinary Research Centre in Biomedical Materials, COMSATS Institute of Information Technology, \\ Lahore-54000, Pakistan \\ f Department of Applied Chemistry, Government College University, Faisalabad-38000, Pakistan
}

*Corresponding author, e-mail: a_naqvi313@yahoo.com

Received 15 Nov 2012

Accepted $27 \mathrm{Feb} 2013$

\begin{abstract}
Biological evaluation of Lantana camara and Justicia adhatoda, belonging to the medicinal plant families Verbenaceae and Acanthaceae, respectively, was performed. Both plants contain a very good range of phenolic compounds $(20.5 \pm 1.9-80.9 \pm 4.1 \mathrm{mg} \mathrm{GAE} / \mathrm{g}$ of dry extract). HPLC analysis of Justicia adhatoda flower and fruit extract showed a broad profile of phenolic acids such as $p$-hydroxy benzoic acid, syringic acid, gallic acid, and quercetin in substantial amounts. The antioxidant study showed moderate to good ability to inhibit linoleic acid peroxidation and to scavenge DPPH free radicals $(67.5 \pm 4.7$ to $80.4 \pm 3.0 \%$ and $71.3 \pm 3.8$ to $85.9 \pm 2.0 \%$, respectively). The antibacterial study reflected good antibacterial potential. This study showed that extracts of flowers and fruits of both plants grown in Soon Skaser Valley, Pakistan have a strong potential to scavenge free radicals and may be used to develop functional food and herbal medicines to treat oxidative stress diseases and bacterial infections.
\end{abstract}

KEYWORDS: reactive oxygen species, lipid peroxidation, Folin-Ciocalteu reagent, Bacillus sp., Staphylococcus sp.

\section{INTRODUCTION}

Several research groups have explored and reported that the presence of reactive oxygen species (ROS) enhances the oxidative stress in a living body which triggers chronic diseases such as asthma, diabetes, cardiovascular diseases, and cancer ${ }^{1-3}$. ROS include a wide range of chemicals, prominently nitric oxide, hydrogen peroxide, superoxide anion, hydroxyl radicals, peroxynitrite anions, alkylperoxyl and hydroperoxyl radicals that are actual cause of degenerative processes in human body ${ }^{4}$. The formation of ROS, an oxidant by-product of normal metabolism, cannot be stopped to form in human body due to inhaling extensive amount of oxygen daily ${ }^{5}$. ROS work in two directions; on one side ROS and immune system work collectively to kill pathogens and on the other side, which is dominant in our environmental conditions, they cause chronic illnesses. However, we can protect human body by creating balance between antioxidants and oxidants. Human defensive system fights against ROS to protect the body from degenerative processes but, when it becomes overwhelmed by an extensive generation of oxidants, our body remains no longer safe from tissue injury via oxidative damage of the proteins, nucleic acids, and lipids. Numerous studies have indicated that daily uptake of antioxidants offer a healthy lifestyle ${ }^{6}$ and impart strength to defensive system of living organisms to nullify the effect of oxidants, by-products of normal body metabolism. In addition to natural foods, it has also been reported that wild plants and agricultural wastes such as olive waste and grape seed extracts have also been successfully applied for the isolation of natural antioxidants on industrial scale $\mathrm{s}^{7,8}$.

In the present study we have selected two wild medicinal plants grown in valley Soon Skaser of Pakistan, Lantana camara L. and Justicia adhatoda which 
belong to family Verbenaceae and Acanthaceae, respectively. The reason to select these plants of different families is that they grow widely in the valley of Soon Skaser and are extensively used in a traditional way to treat ailments. L. camara is a common wild shrub which can grow $2-4 \mathrm{~m}$ in height, native to the American tropics ${ }^{9}$ and extensively planted as an ornamental and hedge plant in Asia. In Pakistan, it commonly grows at $1500 \mathrm{~m}$ altitudes and is known to be used in folk medicines ${ }^{10}$. J. adhatoda grows wild in abundance all over India, Nepal and Pakistan ${ }^{11}$. It is commonly known as Vasaka or Malabar nut with unpleasant smell and bitter taste ${ }^{12}$. The medicinal importance of $J$. adhatoda to treat respiratory disorder can be well understood from the Asian saying "No man suffering from phthisis need despair as long as the Vasaka plant exists" ${ }^{13}$. However, limited studies have been conducted in order to explore the antioxidant and antibacterial activities of its flowers and fruit extracts.

Our aim in this study was to explore the phenolic compounds present in flowers and fruits of J. adhatoda through state-of-the-art technique HPLC, antioxidant, and antibacterial assays of methanolic and ethanolic extracts of flowers and fruits of both plants.

\section{MATERIALS AND METHODS}

\section{Materials}

All chemical and reagents used in this work were of reagent grade. Folin-Ciocalteu's phenol reagent, ascorbic acid, linoleic acid, 1,1-diphenyl-2-picryl hydrazyl (DPPH), trichloroacetic acid, butyl hydroxyl toluene (BHT), gallic acid, butylated hydroxyanisole (BHA) and all phenolic standards were purchased from Sigma-Aldrich Chemical Co. Millipore type filters (pore size $0.22 \mu \mathrm{m}$ and $0.45 \mu \mathrm{m}$ ) were obtained from Sartorius, USA. UV-Vis absorption was measured using a double beam U-2800 UV-Vis spectrometer (HITACHI).

\section{Extraction}

Fully matured flowers and fruits of $L$. camara and $J$. adhatoda were collected from Soon Sakesar valley situated in the central Punjab, Pakistan and specimens were identified at the Department of Botany, Government College University, Faisalabad. Voucher Specimens were deposited at the Department of Botany, Government College University, Faisalabad. The fruits and flowers were manually separated from plants and carefully washed with distilled water to remove unwanted materials and dried in shade. Dried material was ground to obtain 80 mesh size powders.
The powder of fruits and flowers $(20 \mathrm{~g})$ was extracted by mixing $200 \mathrm{ml}$ of $80 \%$ methanol or ethanol using orbital shaker at $200 \mathrm{rpm}$. The extract was filtered using filter paper (Whatman No. 41) and evaporated at low pressure to get dried material. All dried samples were stored at $-4^{\circ} \mathrm{C}$ until further analysis.

\section{Determination of total phenolic compounds}

The total concentration of phenolic compounds in the fruits and flowers extracts was determined according to the method reported by Bozin et al ${ }^{14}$ with slight modification and results were expressed as gallic acid equivalents (GAE). The extracts of fruits and flowers were dissolved (w/v, $0.05 \mathrm{~g} / 2 \mathrm{ml})$ in ethanol. Samples $(1 \mathrm{ml})$ were mixed with 15 -fold diluted solution of Folin-Ciocalteu reagent. The mixture was kept at room temperature for $10 \mathrm{~min}$ followed by the addition of $0.75 \mathrm{ml}$ of $20 \% \mathrm{Na}_{2} \mathrm{CO}_{3}$ (w/v). After subjected to heat in a water bath at $40^{\circ} \mathrm{C}$ for $20 \mathrm{~min}$, the mixture was allowed to cool in an ice-bath at $4{ }^{\circ} \mathrm{C}$. The absorbance of cooled mixture was noted at $755 \mathrm{~nm}$ using double beam U-2800 UV-Vis spectrometer. Amount of TPC was calculated using a calibrated curve for gallic acid (10-130 ppm) in triplicate and results were averaged.

\section{Determination of total flavonoid}

Total flavonoid contents were determined following the procedure described by Bozin et $\mathrm{al}^{14}$. One millilitre of solution containing $0.01 \mathrm{~g} / \mathrm{ml}$ of dry crude extract followed by the addition of $5 \mathrm{ml}$ of distilled water and $0.3 \mathrm{ml}$ of $5 \% \mathrm{NaNO}_{2}$ was placed in a $10 \mathrm{ml}$ volumetric flask. The mixture was incubated for $5 \mathrm{~min}$ and then $0.6 \mathrm{ml}$ of $10 \% \mathrm{AlCl}_{3}$ and $2 \mathrm{ml}$ of $1 \mathrm{M} \mathrm{NaOH}$ were added. The total volume was made up to mark with distilled water. Absorbance was measured at $510 \mathrm{~nm}$. TFC were expressed as catechin equivalents $\mathrm{mg} / 100 \mathrm{~g}$ of dry extract.

\section{HPLC analysis for phenolic compounds}

Phenolic acids were determined by HPLC (Shimadzu) analysis. The extracted sample $(0.025 \mathrm{~g})$ was dissolved in $1 \mathrm{ml}$ methanol followed by passing through membrane filter with $0.45 \mu \mathrm{m}$ pore size and $20 \mu \mathrm{l}$ of filtered solution was then injected into HPLC through sample injection valve. The HPLC system is equipped with a diode array detector $\left(\lambda_{\max }=278 \mathrm{~nm}\right)$ and EclipseXDB-C18 column (Agilent) (dimension: $250 \mathrm{~mm} \times 4.60 \mathrm{~mm}, 5 \mu \mathrm{m})$ operated at $30^{\circ} \mathrm{C}$. The elution solvents were $100 \%$ acetic acid (A) and $100 \%$ acetonitrile (B). The sample was analysed for phenolic compounds using the following gradient elution: $99.2 \% \mathrm{~A}$ in B for $0.1 \mathrm{~min}$ and $90 \% \mathrm{~A}$ in B for $1.0 \mathrm{~min}$ 
Table 1 Extraction yield, total phenolic, and total flavonoid content of methanolic and ethanolic extract of flower and fruits of L. camara and J. adhatoda.

\begin{tabular}{|c|c|c|c|c|c|c|c|}
\hline \multirow[t]{2}{*}{ Sr. no. } & \multirow[t]{2}{*}{ Plant part } & \multicolumn{2}{|c|}{$\begin{array}{c}\text { Yield } \\
\text { (g/100 g dry extract) }\end{array}$} & \multicolumn{2}{|c|}{$\begin{array}{l}\text { Total phenolic contents } \\
\text { (mg/100 g dry extract) }\end{array}$} & \multicolumn{2}{|c|}{$\begin{array}{l}\text { Total flavonoid contents } \\
\text { (mg/100 g dry extract) }\end{array}$} \\
\hline & & methanol & ethanol & methanol & ethanol & methanol & ethanol \\
\hline \multicolumn{8}{|c|}{ Flowers } \\
\hline 1 & L. camara & 10.21 & 5.32 & $50.2 \pm 2.2$ & $30.6 \pm 2.1$ & $20.1 \pm 1.9$ & $10.1 \pm 1.2$ \\
\hline 2 & J. adhatoda & 14.66 & 13.33 & $30.4 \pm 3.3$ & $40.8 \pm 3.2$ & $11.0 \pm 1.2$ & $40.8 \pm 4.1$ \\
\hline \multicolumn{8}{|l|}{ Fruits } \\
\hline 1 & L. camara & 12.66 & 11.33 & $80.9 \pm 4.1$ & $20.5 \pm 1.9$ & $10.1 \pm 1.2$ & $10.6 \pm 1.6$ \\
\hline 2 & J. adhatoda & 14.12 & 11.89 & $40.2 \pm 3.0$ & $50.8 \pm 3.4$ & $10.9 \pm 1.4$ & $10.7 \pm 1.1$ \\
\hline
\end{tabular}

Values are presented as mean \pm S.D. $(n=3)$.

as initial conditions; $70 \% \mathrm{~A}$ in $\mathrm{B}$ for another 1 min followed by $50 \% \mathrm{~A}$ in $\mathrm{B}$ for $35 \mathrm{~min}, 20 \% \mathrm{~A}$ in $\mathrm{B}$ $5 \mathrm{~min}$, and finally $0 \% \mathrm{~A}$ in $\mathrm{B}$ for $5 \mathrm{~min}$. The flow rate of elution was kept at $1 \mathrm{ml} / \mathrm{min}$. Peaks were identified according to the standards run under same conditions.

\section{DPPH free radical scavenging activity}

The potential of scavenging DPPH free radical was also studied using the method reported by Bozin et $\mathrm{al}^{14}$ with slight change. Briefly, $2 \mathrm{ml}$ solution of extract in methanol (w/v, $10 \mathrm{mg}$ per $10 \mathrm{ml}$ methanol) was taken in test tube followed by the addition of equal volume of DPPH solution. All test tubes were put in dark for $30 \mathrm{~min}$. At the end of incubation time the absorbance was noted at $515 \mathrm{~nm}$ using a UV-Vis spectrophotometer. Scavenging activity was calculated as (Absorbance of DPPH solution-Sample absorbance)/(Absorbance of DPPH solution).

\section{Determination of $\%$ inhibition of peroxidation in linoleic acid system}

This study was performed following the method reported by Marxen et al $^{15}$ with slight modifications. A $20 \mathrm{mg}$ sample was mixed to a solution containing linoleic acid $(0.10 \mathrm{ml}), 99.5 \%$ ethanol $(8 \mathrm{ml}), 0.2 \mathrm{M}$ $\mathrm{Na}_{3} \mathrm{PO}_{4}$ buffer of $\mathrm{pH} 7.0(8 \mathrm{ml})$, and the solution was diluted to $20 \mathrm{ml}$ with distilled water followed by incubation for $75 \mathrm{~h}$ at $40{ }^{\circ} \mathrm{C}$. At the end of incubation period the extent of oxidation was measured following thiocyanate method reported by Yen et $\mathrm{al}^{16}$. Briefly, $10 \mathrm{ml} 75 \%$ ethanol, $0.2 \mathrm{ml} 30 \%$ of an aqueous solution of ammonium thiocyanate, $0.2 \mathrm{ml}$ of sample solution, and $20 \mathrm{mM}$ ferrous chloride $\left(\mathrm{FeCl}_{2}\right)$ solution in $4 \%$ $\mathrm{HCl}$ were mixed sequentially. The solution was then stirred for $3 \mathrm{~min}$ and absorbance at $500 \mathrm{~nm}$ was monitored. A blank sample with linoleic acid but without extract sample was taken as negative control while BHT was used as a positive control. The minimum peroxidation level was measured after $75 \mathrm{~h}$ (3 days) in the blank sample. The inhibition of linoleic acid per oxidation was calculated as $1-$ (Abs. increase of sample at $75 \mathrm{~h}) /($ Abs. increase of control at $75 \mathrm{~h})$.

\section{Antibacterial potential assay}

Antibacterial potential of each extract was determined by following a reported method ${ }^{17}$. For inoculation, liquid culture of 4 selected bacteria $(100 \mu \mathrm{l})$ with optical density value $1.4-1.6$ at $600 \mathrm{~nm}$ was used to inoculate $10 \mathrm{ml} \mathrm{LB}$ medium having no extract $(0 \mu \mathrm{g}$ as control), $12.5 \mu \mathrm{g}, 25 \mu \mathrm{g}, 37.5 \mu \mathrm{g}$, and $50 \mu \mathrm{g}$ of each flower and fruit extract. In order to grow all four bacterial strains, all tubes were incubated at $37{ }^{\circ} \mathrm{C}$ for $24 \mathrm{~h}$. On completion of the incubation period, the optical density of each growing strain was recorded with a UV-Vis spectrophotometer at $600 \mathrm{~nm}$.

\section{RESULTS}

\section{Extract yield, phenolic acid and flavonoid compounds determination}

Table 1 shows the yields, total phenolic acids and total flavonoid compounds of methanolic and ethanolic extracts of flowers and fruits. The amounts of extractable substances were expressed as percentage by weight of dried flowers and fruits. Total phenolic and total flavonoid contents were also present in appreciable quantity and were expressed as GAE.

\section{HPLC analysis for phenolic acids}

The HPLC patterns of different phenolic acid present in extracts of $J$. adhatoda flowers and fruits were analysed by comparing the peaks of standard phenolic compounds. Comparison was performed with eleven biologically important phenolic acids and the results were summarized in Table 2. 
Table 2 HPLC analysis of methanolic extracts of flowers and fruits of J. adhatoda for phenolic acids.

\begin{tabular}{|c|c|c|c|c|c|c|}
\hline \multirow[t]{2}{*}{ No. } & \multirow[t]{2}{*}{ Standards } & \multirow{2}{*}{$\begin{array}{l}\text { Retention time } \\
\qquad(\min )\end{array}$} & \multicolumn{2}{|c|}{ Flowers } & \multicolumn{2}{|c|}{ Fruits } \\
\hline & & & $\begin{array}{l}\text { Retention time } \\
\qquad(\min )\end{array}$ & $\begin{array}{l}\text { Concentration } \\
(\mathrm{mg} / 100 \mathrm{~g})\end{array}$ & $\begin{array}{l}\text { Retention time } \\
\qquad(\min )\end{array}$ & $\begin{array}{c}\text { Concentration } \\
(\mathrm{mg} / 100 \mathrm{~g})\end{array}$ \\
\hline 1 & vanillic acid & 5.343 & $5.33 \pm 0.03$ & $10.50 \pm 0.32$ & $5.30 \pm 0.05$ & $2.68 \pm 0.25$ \\
\hline 2 & tannic acid & 6.000 & $5.901 \pm 0.012$ & $1.33 \pm 0.21$ & $5.93 \pm 0.08$ & $1.17 \pm 0.12$ \\
\hline 3 & ellagic acid & 6.436 & - & ND & $6.50 \pm 0.09$ & $2.15 \pm 0.14$ \\
\hline 4 & 3,4-dihydroxy benzoic acid & 9.178 & $9.26 \pm 0.06$ & $1.98 \pm 0.11$ & - & ND \\
\hline 5 & syringic acid & 10.401 & $10.52 \pm 0.04$ & $3.13 \pm 0.19$ & $10.38 \pm 0.06$ & $5.64 \pm 0.41$ \\
\hline 6 & p-hydroxy benzoic acid & 11.707 & $11.77 \pm 0.08$ & $6.84 \pm 0.25$ & $11.80 \pm 0.09$ & $372.1 \pm 4.7$ \\
\hline 7 & ferulic acid & 15.754 & - & ND & $15.81 \pm 0.08$ & $1.54 \pm 0.13$ \\
\hline 8 & quercetin & 22.345 & - & ND & $22.42 \pm 0.10$ & $1.65 \pm 0.19$ \\
\hline 9 & caffeic acid & 38.151 & - & ND & - & ND \\
\hline 10 & gallic acid & 48.797 & $48.69 \pm 0.04$ & $2.89 \pm 0.17$ & - & ND \\
\hline 11 & $p$-coumaric acid & 49.112 & $49.10 \pm 0.04$ & $1.80 \pm 0.09$ & - & ND \\
\hline
\end{tabular}

The values are presented as mean \pm S.D $(n=3)$; ND $=$ not detected.

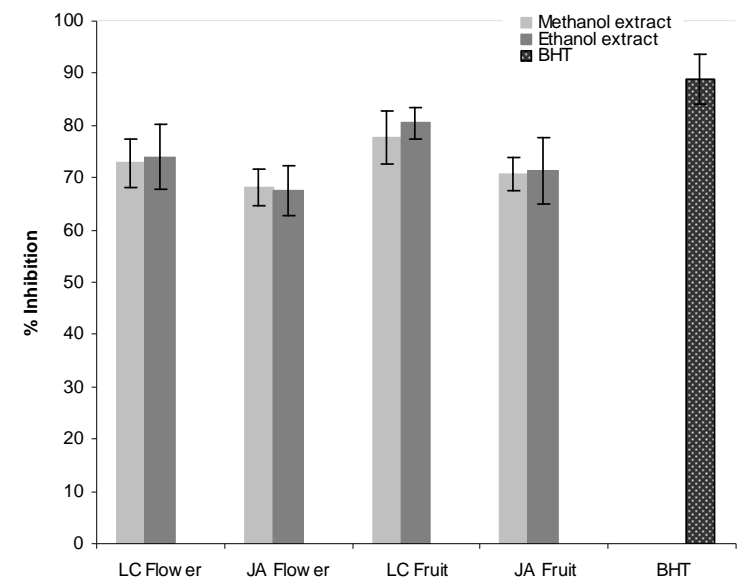

Fig. 1 DPPH free radical scavenging potential of phenolic acids in the methanol and ethanol extracts of flowers and fruits of L. camara and J. adhatoda.

\section{DPP free radical scavenging activity}

Fig. 1 explained the DPPH free radical scavenging ability of flowers and fruits of both plants. Methanol extract of $L$. camara flower and J. adhatoda fruit showed $83.2 \pm 3.6$ and $85.9 \pm 2 \%$ scavenging activity, respectively. However, ethanolic extract contained less phenolic acids and less free radical scavenging potential as compared to methanolic extract except J. adhatoda fruit extract that showed $82.6 \pm 4 \%$ activity.

\section{Inhibition of linoleic acid peroxide}

The data obtained by performing linoleic acid peroxide inhibition was shown in Fig. 2. All the extracts except that of $J$. adhatoda flower showed promising

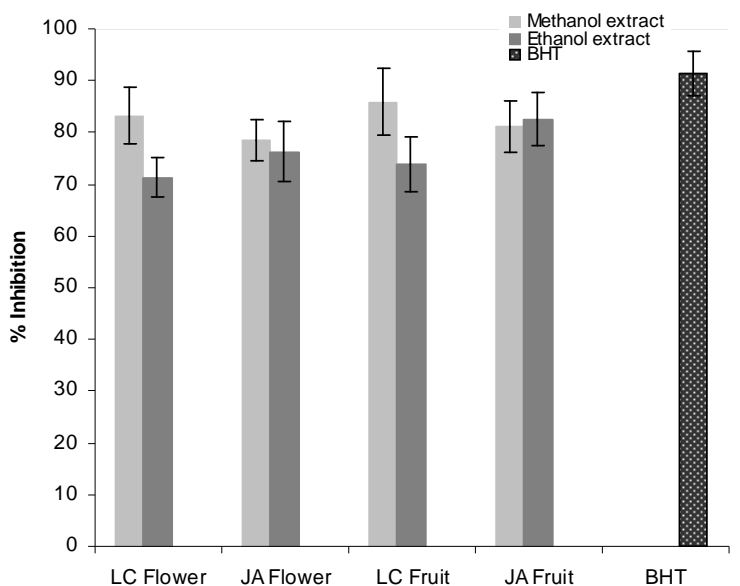

Fig. 2 Percent inhibition of linoleic acid oxidation by methanol and ethanol extracts of flowers and fruits of L. camara and J. adhatoda.

inhibition of linoleic acid peroxidation. However the observed \% inhibition of linoleic acid peroxidation for all extracts was less than for the reference compound (BHT).

\section{Antibacterial activity}

In the antibacterial assays, extracts of L. camara and $J$. adhatoda flowers and fruits were also evaluated for their antibacterial activities against four bacterial strains, viz., Bacillus sp., Staphylococcus sp., Streptococcus sp., and E. coli. Overall all extracts showed biological activity in terms of $50 \%$ inhibition of bacterial growth with reference to control (devoid of plant extract) in concentration range $25.0 \mu \mathrm{g}$ to $37.5 \mu \mathrm{g}$ (Table 3). 
Table 3 Antibacterial activity in terms of $\mathrm{IC}_{50}$ values of methanolic and ethanolic extracts of flowers and fruits of $L$. camara and $J$. adhatoda.

\begin{tabular}{|c|c|c|c|c|c|c|c|c|}
\hline \multirow[t]{3}{*}{ Microorganism } & \multicolumn{4}{|c|}{ L. camara $\mathrm{IC}_{50}(\mu \mathrm{g})$} & \multicolumn{4}{|c|}{ J. adhatoda $\mathrm{IC}_{50}(\mu \mathrm{g})$} \\
\hline & \multicolumn{2}{|c|}{ flower extract } & \multicolumn{2}{|c|}{ fruit extract } & \multicolumn{2}{|c|}{ flower extract } & \multicolumn{2}{|c|}{ fruit extract } \\
\hline & $\mathrm{MeOH}$ & $\mathrm{EtOH}$ & $\mathrm{MeOH}$ & $\mathrm{EtOH}$ & $\mathrm{MeOH}$ & $\mathrm{EtOH}$ & $\mathrm{MeOH}$ & $\mathrm{EtOH}$ \\
\hline Bacillus sp. & 25.0 & 37.5 & 37.5 & 50.0 & 37.5 & 25.0 & 50.0 & 50.0 \\
\hline Staphylococcus sp. & 37.5 & 37.5 & 50.0 & 37.5 & 25.0 & 25.0 & 37.5 & 37.5 \\
\hline Streptococcus sp. & 25.0 & 25.0 & 50.0 & 50.0 & 25.0 & 25.0 & 50.0 & 50.0 \\
\hline E. coli & 37.5 & 37.5 & 37.5 & 37.5 & 37.5 & 37.5 & 50.0 & 50.0 \\
\hline
\end{tabular}

$\mathrm{MeOH}=$ methanol, EtOH = ethanol.

\section{DISCUSSION}

The yields of extracts obtained from flower and fruits of both plants were in good quantity (5\% to $15 \%$ ). Methanol was found to be the solvent of choice to extract plant contents better than ethanol. Methanol extract of L. camara exhibited significant phenolic acid contents in case of flowers and fruits while flower and fruits of $J$. adhatoda showed lowest TPC in case of methanol extract and higher in the case of ethanol extracts. From the data obtained, methanol was found to be the effective solvent for the extraction of phenolic components. Previously reported data also recommend methanol as the better solvent for phenolic compounds extraction ${ }^{18,19}$. However, TFC was obtained in good yield in the ethanol extract of $J$. adhatoda flower $(40.8 \pm 4.1 \mathrm{mg} / 100 \mathrm{~g})$ followed by the methanol extract of $L$. camara flower $(20.1 \pm 1.9 \mathrm{mg} / 100 \mathrm{~g})$. All other extracts exhibited low quantity of TFC (Table 1). In order to detect phenolic acids, eleven phenolic acids in extracted samples were run as reference standards on HPLC before analyzing the flower and fruits extract of J. adhatoda. The analysis showed that $p$-hydroxy benzoic acid was present in significant amount $(372.1 \mathrm{mg} / 100 \mathrm{~g}$ dry extract) in $J$. adhatoda fruit extract but in small quantity $(11.77 \mathrm{mg} / 100 \mathrm{~g}$ dry extract) in $J$. adhatoda flower extract. Other important phenolic acids such as syringic acid, $p$-hydroxybenzoic acid, quercetin, gallic acid and $p$-coumaric acid were also detected in both sample extracts (Table 2).

Plants may carry number of classes of biological active compounds but the presence of phenolic compounds in plants defines their medicinal importance ${ }^{20}$. Phenolic acids are predominantly associeated with antioxidant activities predominantly by scavenging free radicals produced in the human body. For in vitro free radical scavenging model, DPPH free radical is widely used to investigate antioxidant potential of natural material extracts ${ }^{21}$. Methanol extracts of
L. camara showed significant DPPH free radical scavenging ability $(>85 \%)$ as compared to $J$. adhatoda extracts $(<80 \%)$. Anyhow, all extracts showed good DPPH free radical scavenging activity.

Further confirmation of antioxidant activity was assessed using inhibition of linoleic acid peroxidation. Ethanol extract of L. camara fruit showed $>80 \%$ inhibition of linoleic acid peroxidation, followed by its methanol fruit extract. Other extracts showed inhibition in the range of $67-73 \%$ (Fig. 2). However, overall antioxidant results demonstrated good correlation between phenolic compounds and antioxidant activity. The closely related correlation has also been reported earlier in other reports ${ }^{22-24}$.

Antibacterial activity of all extracts showed $50 \%$ inhibition of bacterial growth in the range of $25-50 \mu \mathrm{g}$ (Table 3). Flower extracts in methanol and ethanol of both plants showed good inhibition against bacterial growth. Bacillus sp. and Streptococcus sp. were more susceptible to L. camara flower extracts while Staphylococcus sp. and Streptococcus sp. to J. adhatoda flower extracts. However the fruit extracts showed relatively low antibacterial activity $\left(\mathrm{IC}_{50}=37.5-\right.$ $50.0 \mu \mathrm{g}$ ). Most of them showed $\mathrm{IC}_{50}=50.0 \mu \mathrm{g}$, which exhibited weak antibacterial effect. Our findings are in good agreement with the antibacterial potential of extracts of both parts of L. camara and J. adhatoda against different strains of bacteria ${ }^{12,25,26}$.

\section{CONCLUSIONS}

Biological evaluation of flowers and fruits of medicinal important shrubs L. camara and J. adhatoda in term of antioxidant and antibacterial potential revealed that the extract could be used to prepare herbal medicines. Further the isolation of individual components could be used to derive more active compound to combat diseases caused by oxidative stress and bacterial infection. 
Acknowledgements: The authors would like to acknowledge the Higher Education Commission for providing financial grant for completion of this study.

\section{REFERENCES}

1. Paravicini TM, Touyz RM (2008) NADPH oxidases, reactive oxygen species, and hypertension: clinical implications and therapeutic possibilities. Diabetes Care 2, S170-80.

2. Klaunig JE, Kamendulis LM (2004) The role of oxidative stress in carcinogenesis. Annu Rev Pharmacol Toxicol 44, 239-67.

3. Zhang L, Wang M, Kang X, Boontheung P, Ning L, Andre E, Joseph AL (2009) Oxidative stress and asthma: Proteome analysis of chitinase-like proteins and FIZZ1 in lung tissue and bronchoalveolar lavage fluid. J Proteome Res 8, 1631-8.

4. Wang SY, Kuo YH, Chang HN, Kang PL, Tsay HS,Lin KF, Yang NS, Shyur LF (2002) Profiling and characterization antioxidant activities in Anoectochilus formosanus Hayata. J Agr Food Chem 50, 1859-65.

5. Tai Z, Cai L, Dai L, Dong L, Wang M, Yang Y, Cao Q, Ding Z, et al(2011) Antioxidant activity and chemical constituents of edible flower of Sophora viciifolia. Food Chem 126, 1648-54.

6. Vági E, Rapavi E, Hadolin M, Vásárhelyiné Perédi K, Balázs A, Blázovics A, Simándi B (2005) Phenolic and triterpenoid antioxidants from Origanum majorana L. herb and extracts obtained with different solvents. $J \mathrm{Agr}$ Food Chem 53, 17-21.

7. Nuamsetti $T$, Dechayuenyong $P$, Tantipaibulvut $S$ (2012) Antibacterial activity of pomegranate fruit peels and arils. Sci Asia 38, 319-22.

8. Peschel W, Dieckmann W, Sonnenschein M, Plescher A (2007) High antioxidant potential of pressing residues from evening primrose in comparison to other oilseed cakes and plant antioxidants. Ind Crop Prod 25, 44-54.

9. United States Department of Agriculture (2007) Lantana camara L. Germplasm Resources Information Network. 2007-05-29.

10. Hussain F, Ghulam S, Sher Z, Ahmad B (2011) Allelopathy by Lantana camara L. Pakistan J Bot 43, 2373-8.

11. Chakrabart A, Brantner AH (2001) Study of alkaloids from Adhatoda vasica Nees on their antiinflammatory activity. Phytother Res 15, 532-4.

12. Dhankhar S, Kaur R, Ruhil S, Balhara M, Dhankhar S, Chillar AK (2011) A review on Justicia adhatoda: A potential source of natural medicine. Afr J Plant Sci $\mathbf{5}$, $620-7$.

13. Dymock W, Warden C, Hooper D (1893) Pharmacographia India. A History of the Principal Drug of Vegetable Origin Met with in British India (London: Kegan, Paul, Trench, Trubner and Co), pp 49-51.

14. Bozin B, Mimica-Dukie N, Simin N, Anackov G
(2006) Characterization of the volatile composition of essential oil of some lamiaceae species and the ntimicrobial and antioxidant activities of the entire oils. J Agr Food Chem 54, 1822-8.

15. Marxen K, Vanselow KH, Lippemeier S, Hintze R, Ruser A, Hansen U (2007) Determination of DPPH radical oxidation caused by methanolic extracts of some microalgal species by linear regression analysis of spectrophotometric measurements. Sensors 7, 2080-95.

16. Yen GC, Duh PD, Chuang DY (2000) Antioxidant activity of anthraquinones and anthrone. Food Chem 70, 437-41.

17. Mahmood N, Allah Ditta S, Zameer M (2011) Biochemical screening of different local fungi for their comparitive antibacterial potential. Int J Agro Vet Med Sci 5, 322-6.

18. Hertog MGL, Hollman PCH, Van de Putte B (1993) Contents of potentially anticarcenogenic flavonoids of tea infusions, wines and fruit juices. J Agr Food Chem 41, 1242-6.

19. Yen G, Wu S, Duh P (1996) Extraction and identification of antioxidant componnts from the leaves of mulberry (Morus alba L.). J Agr Food Chem 44, 1687-90.

20. Rice-Evans CA, Miller NJ, Paganga G (1996) Structure-antioxidant activity relationship of flavonoids and phenolic acids. Free Radic Biol Med 20, 933-56.

21. Porto CD, Calligaris S, Cellotti E, Nicoli MC (2000) Antiradical properties of commercial cognacs assessed by the DPPH test. J Agr Food Chem 48, 4241-5.

22. Gao X, Ohlander M, Jeppsson N, Bjrk L, Trajkovski V (2000) Changes in antioxidant effects and their relationship to phytonutrients in fruits of sea buckthorn (Hippophae rhamnoides L.) during maturation. J Agr Food Chem 48, 1485-90.

23. Zheng W, Wang S (2001) Antioxidant activity and phenolic composition in selected herbs. J Agr Food Chem 49, 5165-70.

24. Arabshahi-Delouee S, Urooj A (2007) Antioxidant properties of various solvent extracts of mulberry (Morus indica L.) leaves. Food Chem 102, 1233-40.

25. Ganjewala D, Sam S, Khan KH (2009) Biochemical compositions and antibacterial activities of Lantana camara plants with yellow, lavender, red and white flowers. EurAsia J BioSci 3, 69-77.

26. Badakhshan MP, Sasidharan S, Rameshwar NJ, Ramanathan S (2009) A comparative study: Antimicrobial activity of methanol extracts of Lantana camara various parts. Pharmacognosy Res 1, 348-51. 